\title{
Bioactive Cytokinins Are Selectively Secreted by Sinorhizobium meliloti Nodulating and Nonnodulating Strains
}

\author{
Anna Kisiala, ${ }^{1,2}$ Carole Laffont, ${ }^{3}$ R. J. Neil Emery, ${ }^{1}$ and Florian Frugier ${ }^{3}$ \\ ${ }^{1}$ Biology Department, Trent University, 2140 East Bank Drive, Peterborough K9J 7B8, Canada; ${ }^{2}$ Department of Genetics and \\ Plant Biotechnology, University of Technology and Life Sciences, 85-789 Bydgoszcz, Poland; ${ }^{3}$ Institut des Sciences du Végétal \\ (ISV), CNRS, avenue de la Terrasse, 91198 Gif-sur-Yvette cedex, France
}

Submitted 22 February 2013. Accepted 26 April 2013.

\begin{abstract}
Bacteria present in the rhizosphere of plants often synthesize phytohormones, and these signals can consequently affect root system development. In legumes, plants adapt to nitrogen starvation by forming lateral roots as well as a new organ, the root nodule, following a symbiotic interaction with bacteria collectively referred to as rhizobia. As cytokinin (CK) phytohormones were shown to be necessary and sufficient to induce root nodule organogenesis, the relevance of CK production by symbiotic rhizobia was questioned. In this study, we analyzed quantitatively, by liquid chromatography-tandem mass spectrometry, the production of 25 forms of $\mathrm{CK}$ in nine rhizobia strains belonging to four different species. All bacterial strains were able to synthesize a mix of CK, and bioactive forms of CK, such as iP, were notably found to be secreted in bacterial culture supernatants. Use of a mutant affected in extracellular polysaccharide (EPS) production revealed a negative correlation of EPS production with the ability to secrete CK. In addition, analysis of a nonnodulating Sinorhizobium meliloti strain revealed a similar pattern of CK production and secretion when compared with a related nodulating strain. This indicates that bacterially produced CK are not sufficient to induce symbiotic nodulation.
\end{abstract}

Soil bacteria surrounding the plant root system, so-called rhizospheric bacteria, frequently produce plant hormones that can affect root growth and development. Plant growth-promoting rhizobacteria (PGPR) producing auxins, cytokinins (CK), ethylene inhibitors, and gibberellins influence root system growth (Saharan and Nehra 2011). This includes Bacillus spp., Pseudomonas spp., and Azotobacter spp. that produce the indole acetic acid (IAA) auxin modulating root growth. Another example is pathogenic bacteria manipulating plant hormonal balances to affect host growth and development. Agrobacterium spp. can transfer into the plant genome a DNA fragment encoding for auxin and CK hormonal biosynthetic genes, leading to the formation of "crown galls" or "hairy roots" on various host plants. In the case of Rhodococcus fascians, production of a specific mix of different types of CK hormones was linked to its pathogenicity by altering plant defense, stress, and developmental responses (Depuydt et al. 2009; Pertry et al.

Corresponding authors: R. J. N. Emery; E-mail: nemery@trentu.ca and F. Frugier; E-mail: frugier@ isv.cnrs-gif.fr

(C) 2013 The American Phytopathological Society
2009; Stes et al. 2011). Concerning symbiotic bacteria, rhizobia are among the most active IAA producers and, therefore, PGPR inducers of root system development. In addition, rhizobia interact with specific legume host plants to generate new organs on the root system, the root nodules, in which differentiated symbiotic bacteria will fix atmospheric nitrogen for the benefit of the host plant. Bradyrhizobium japonicum mutants overproducing auxin are not only beneficial for root growth but they also promote symbiotic nodulation. Conversely, Bradyrhizobium elkanii mutants deficient in IAA production have decreased nodulation (Kaneshiro and Kwolek 1985; Fukuhara et al. 1994). A more recent study, however, revealed that mutants inhibiting IAA production in the broad-host-range Rhizobium sp. strain NGR234 did not show an altered nodulation efficiency (Theunis et al. 2004). Qualitative analyses additionally showed that Rhizobium leguminosarum and B. japonicum were able to produce and secrete bioactive CK, such as zeatin, at concentrations that could affect root development (Phillips and Torrey 1972; Sturtevant and Taller 1989; Boiero et al. 2007). However, no direct evidence, such as identification of CKdeficient bacterial mutants, links rhizobial $\mathrm{CK}$ production to plant nodulation ability. In contrast, production by rhizobia of lipochitooligosaccharide signaling molecules, the Nod(ulation) factors, was genetically demonstrated to be essential for nodulation and, additionally, responsible for the high host specificity of symbiotic interactions with rhizobia (Roche et al. 1991). Indeed, mutation in any bacterial enzyme essential to generate Nod factors, encoded by nod genes, leads to a strict nonnodulating ( od $^{-}$) phenotype on host plants. The critical role of CK in nodulation was, however, more recently unambiguously revealed through the identification of plant MtCRE1/ LHK1 (CK response 1/histidine kinase 1) CK receptors as necessary and sufficient for nodule organogenesis (Gonzalez-Rizzo et al. 2006; Murray et al. 2007; Plet et al. 2011; Tirichine et al. 2007). Together with the identification of specific photosynthetic Bradyrhizobia species that do not encode $N O D$ genes in their genome (Giraud et al. 2007), these studies renewed interest for analyzing relevance of bacterially produced CK in triggering symbiotic nodulation (Frugier et al. 2008).

In this study, we have performed a detailed quantitative analysis of CK synthesis and secretion in four different rhizobia species, using a very sensitive liquid chromatography (LC)-positive electrospray ionization (ES+) tandem mass spectrometry (MS/MS) methodology. This revealed that all nine rhizobia strains tested are able to produce and secrete a mix of $\mathrm{CK}$, including bioactive forms such as iP and trans-zeatin. A nod Sinorhizobium meliloti strain was, however, still able to 
secrete a similar CK mix as that of a related nodulating strain, indicating that bacterially produced $\mathrm{CK}$ are not sufficient to allow nodulation.

\section{RESULTS}

Reference strains of $S$. meliloti, S. fredii, S. medicae, and Mesorhizobium loti (Table 1) were cultured in vitro until they reached a density at which there were sufficient cells for LCMS/MS analysis of endogenous $\mathrm{CK}$ production and of $\mathrm{CK}$ release in the culture medium. In contrast to previous studies, bacteria were grown in a GTS minimal medium containing only mineral compounds (Kiss et al. 1979) and, therefore, not contaminated by $\mathrm{CK}$, such as iP, their precursors or derivatives, as this is the case for media containing yeast extract (data not shown).

All the wild-type (WT) strains analyzed were able to synthesize CK, and among the 25 different compounds analyzed, 11 were successfully detected and classified as four CK types (free bases, ribosides, nucleotides, and methyl-thiol derivatives; Table 2). In contrast to previous studies, we determined relative CK content after centrifugation separately in bacterial cell pellets (Fig. 1A) and bacterial supernatants (Fig. 1B). All samples were normalized against the number of bacterial cells. Cell pellets of the four $S$. meliloti strains as well as the $S$. medicae strain presented similar $\mathrm{CK}$ production patterns. They differed slightly from $S$. fredii and $M$. loti, for which the free bases (CK-FB) exceeded $10 \%$ of total CK, two to three times greater than that of the other five strains (Fig. 1A). The predominating CK type in bacterial cells (pellet) of all tested rhizobia strains were methyl-thiols (CK-MET), which consistently made up more than $60 \%$ of all CK detected (Fig. 1A). The relative levels of CK-MET released to the medium were, however, only about 1.1-fold greater than those detected in the bacterial cells, while the CK-FB level in supernatants were at least 1.6-fold higher in the case of Sm10234R, around three times higher for $S$. fredii and $M$. loti, and almost 10-fold higher for Sm1021 (Fig. 1A and B). Interestingly, CK profiles of all bacterial supernatants were found to contain markedly more CK-FB than cell pellets, and in the case of S. fredii and M. loti, this type of CK represented over $40 \%$ of the total CK released (Fig. 1B). By contrast, nucleotides (CK-NT) and ribosides (CK-RB) were present almost exclusively in bacterial cells and were detected in the medium only in minute quantities.

To investigate the potential role of $\mathrm{CK}$ produced by rhizobia in relation to symbiotic nodulation in addition to the welldescribed function of Nod-factor signaling molecules, a detailed analysis of CK produced by $S$. meliloti nodulating strains (Rm41 and the AK631 exo derivative) versus a nonnodulating strain showing a large deletion affecting several nod genes (ZB138; Kondorosi et al. 1984) was performed. The LC-

(ES+)MS/MS analyses revealed that all three $S$. meliloti strains were able to synthesize and secrete a mix of CK (Table 3; Fig. 2). The most abundant CK type again corresponded to MET forms, represented mainly by $2 \mathrm{MeSZ}$ and $2 \mathrm{MeSiP}$. CK-FB were also identified in all cases within bacterial cells and as secreted in the medium, corresponding mainly to iP. Comparative analysis of these rhizobia mutant strains reveals that mutations in extracellular polysaccharide (EPS) extracellular polysaccharides and Nod factor production do not abolish rhizobial production of CK. In the cell pellet of the nod $^{-}$mutant ZB138, a CK mix similar to that of the WT and AK631 exo nodulating strains was recovered (no significant differences identified between strains for the four main CK groups; Duncan's multiple range test, $P<0.05$ [Table 3; Fig. 2]). Interestingly, com-

Table 2. Cytokinins (CK) scanned for by liquid chromatography-positive electrospray ionization tandem mass spectrometry in rhizobia cells and supernatants $^{\mathrm{a}}$

\begin{tabular}{|c|c|}
\hline CK & Labeled CK standard \\
\hline $\begin{array}{l}\text { Nucleotides } \\
\text { Trans-zeatin riboside-5'-monophosphate } \\
\text { Cis-zeatin riboside-5'-monophosphate } \\
\text { Dihydrozeatin riboside }-5 \text { '-monophosphate } \\
\mathbf{N}^{6} \text {-isopentyladenosine-5'monophosphate }\end{array}$ & $\begin{array}{l}{ }^{2} \mathrm{H}_{3}[9 \mathrm{RMP}] \mathrm{DHZ} \\
{ }^{2} \mathrm{H}_{6}[9 \mathrm{RMP}] \mathrm{iP}\end{array}$ \\
\hline $\begin{array}{l}\text { Ribosides } \\
\text { Trans-zeatin riboside } \\
\text { Cis-zeatin riboside } \\
\text { Dihydrozeatin riboside } \\
\mathbf{N}^{6} \text {-isopentyladenosine }\end{array}$ & $\begin{array}{l}{ }^{2} \mathrm{H}_{5}[9 \mathrm{R}] \mathrm{Z} \\
{ }^{2} \mathrm{H}_{3}[9 \mathrm{R}] \mathrm{DHZ} \\
{ }^{2} \mathrm{H}_{6}[9 \mathrm{R}] \mathrm{iP}\end{array}$ \\
\hline $\begin{array}{l}\text { Free bases } \\
\text { Trans-zeatin* } \\
\text { Cis-zeatin } \\
\text { Dihydrozeatin } \\
\mathbf{N}^{6} \text {-isopentyladenine }\end{array}$ & $\begin{array}{l}{ }^{2} \mathrm{H}_{5} \mathrm{Z} \\
{ }^{2} \mathrm{H}_{3} \mathrm{DHZ} \\
{ }^{2} \mathrm{H}_{6} \mathrm{iP}\end{array}$ \\
\hline $\begin{array}{l}\text { Glucosides } \\
\text { trans-Zeatin- } O \text {-glucoside } \\
\text { cis-Zeatin- } O \text {-glucoside } \\
\text { Dihydrozeatin- } O \text {-glucoside } \\
\text { trans-Zeatin- } O \text {-glucoside riboside } \\
\text { cis-Zeatin- } O \text {-glucoside riboside } \\
\text { Dihydrozeatin- } O \text {-glucoside riboside } \\
\text { trans-Zeatin-9-glucoside } \\
\text { cis-Zeatin-9-glucoside } \\
\text { Dihydrozeatin-9-glucoside (DHZ9G) }\end{array}$ & $\begin{array}{l}{ }^{2} \mathrm{H}_{5} \mathrm{ZOG} \\
{ }^{2} \mathrm{H}_{7} \mathrm{DHZOG} \\
{ }^{2} \mathrm{H}_{5} \mathrm{ZROG} \\
{ }^{2} \mathrm{H}_{7} \mathrm{DHZROG} \\
{ }^{2} \mathrm{H}_{5} \mathrm{Z} 9 \mathrm{G} \\
{ }^{2} \mathrm{H}_{3} \mathrm{DHZ} 9 \mathrm{G}\end{array}$ \\
\hline $\begin{array}{l}\text { Methyl-thiols } \\
\text { 2-Methylthio-trans-zeatin } \\
\text { 2-Methylthio-trans-zeatin riboside } \\
\text { 2-Methylthio-N }{ }^{6} \text {-isopentyladenine } \\
\text { 2-Methylthio- }{ }^{6} \text {-isopentyladenosine }\end{array}$ & $\begin{array}{l}{ }^{2} \mathrm{H}_{5} \mathrm{MeSZ} \\
{ }^{2} \mathrm{H}_{5} \mathrm{MeSZR} \\
{ }^{2} \mathrm{H}_{6} \mathrm{MeSiP} \\
{ }^{2} \mathrm{H}_{6} \mathrm{MeSiPA}\end{array}$ \\
\hline
\end{tabular}

Table 1. Wild type and mutant strains of Rhizobium spp. used in this study

\begin{tabular}{lll}
\hline Strain & \multicolumn{1}{c}{ Description } & Reference or source \\
\hline Sinorhizobium (Ensifer) meliloti & & Kondorosi et al. 1984 \\
Rm41 (Exo+ Nod+) & Wild type (WT), nodulating Medicago spp. & Kondorosi et al. 1984 \\
AK631 (Exo-Nod+) & Mutant derived from Rm41, nodulating Medicago spp. & Kondorosi et al. 1984 \\
ZB138 (Exo-Nod-) & Nonnodulating mutant derived from AK631 & Meade and Singer 1977 \\
Sm2011 & WT, nodulating Medicago spp. & Leigh et al. 1985 \\
Sm1021 & WT, nodulating Medicago spp. & Pocard et al. 1997 \\
Sm102F34R & WT, nodulating Medicago spp. & Noreen et al. 2003 \\
Sinorhizobium (Ensifer) fredii & WT, nodulating Medicago spp. & Rome et al. 1996 \\
HH103 & WT, nodulating Medicago spp. & Szczyglowski et al. 1998 \\
Sinorhizobium (Ensifer) medicae & & \\
LMG19920 (=A321= Willems R-916) & WT, nodulating Lotus spp. & \\
Mesorhizobium loti & & \\
NZP2235 & &
\end{tabular}


pared with the WT, significantly lower levels of secreted CK were detected in both exo $^{-}$mutants (AK631 and ZB138) (Table 3; Fig. 2), independently of their ability to nodulate. This suggests that, whereas none of the mutants tested directly suppress bacterial CK synthesis, a lack of EPS secretion is correlated with a reduced $\mathrm{CK}$ release.

\section{DISCUSSION}

The aim of this study was to analyze the ability of different rhizobia species to synthesize and secrete CK, which are essen- tial to induce the formation of symbiotic nitrogen-fixing nodules on legume host plants. We first showed that the four different species and nine strains analyzed were able to produce and release mixtures of $\mathrm{CK}$ in the medium. This is consistent with earlier publications that reported $\mathrm{CK}$ in supernatants of various rhizobial strains (Boiero et al. 2007; Phillips and Torrey 1972; Sturtevant and Taller 1989). However, these previous studies tracked only a few selected CK forms (only up to four different $\mathrm{CK}$ detected in a single assay, depending on analyses). More efficient techniques of hormone extraction and considerably greater sensitivity are now available (Farrow and
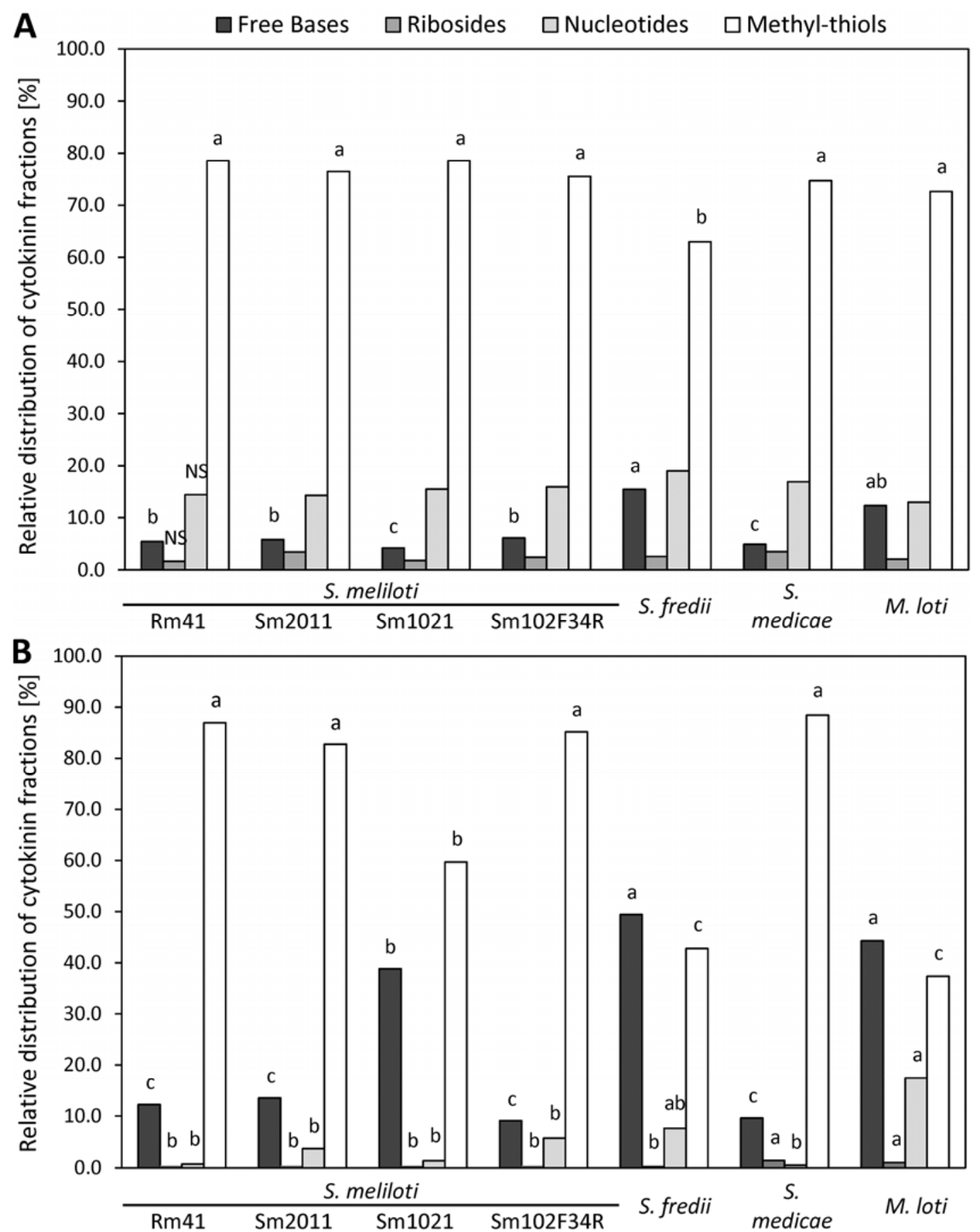

Fig. 1. Cytokinin (CK) distribution in seven Rhizobia strains. Bacterial cells of different WT strains nodulating Medicago spp. (S. meliloti, S. fredii and S. medicae) or Lotus spp. (M. loti) host plants were centrifuged. A, Bacterial cell pellets and B, supernatants were analyzed by liquid chromatography-tandem mass spectrometry separately for CK contents. The concentration of CK types (FB, RB, NT, MET) in different wild-type (WT) strains is expressed as a percentage share of the total CK pool that was produced (A) and secreted (B). A Duncan's multiple range test was performed to determine significant differences between strains for each CK type. Means are followed by letters only when significant differences were detected at the rejection level $P=0.05$. NS indicates lack of significant differences between the strains. 
Emery 2012), allowing us to determine the profile of 25 different CK compounds, out of which 11 were successfully detected in bacterial samples. In addition, the present study aimed to analyze bacterial supernatants and cell pellets separately, to more completely address the complexity of rhizobial CK metabolism.

CK-MET was the main CK type detected in all rhizobia cells tested as well as in most supernatants, and this was independent of the species (S. meliloti, S. fredii, S. medicae, or M. loti) or strains. This agrees with previous reports showing that high levels of CK-MET are characteristic of several rhizospheric microorganisms, including symbionts such as rhizobia (Phillips and Torrey 1972; Sturtevant and Taller 1989) and pathogens such as Rhodococcus fasciens when they interact with plants (Eason et al. 1996; Pertry et al. 2009). The high contribution of CK-MET relative to the total amount of CK detected in supernatants likely reflects their high production rate. The relative levels of CK-MET released to the medium were, however, proportionally much reduced compared with levels of CK-FB detected in supernatants. This indicates that CK-MET are not preferentially secreted from the bacterial cells, suggesting that, despite being the predominant type of rhizobial CK, they may not, by themselves, be the most important signaling molecules acting in the rhizosphere. Similarly, nearly all CK-NT and CK$\mathrm{RB}$, considered to be less biologically active, were found as retained in bacterial cells, in which they could possibly be used as storage forms (Romanov 2011; Sakakibara 2006). Accordingly, cisZ derivatives were detected in CK-NT and CK-RB fractions, as observed in earlier reports, confirming that cis isomers of CK are abundant in microorganisms (Eason et al. 1996; Lichter et al. 1995; Pertry et al. 2009; Stevens and Berry 1988; Timmusk et al. 1999). The clearest differences between CK types found in bacteria versus those secreted in the medium were observed with CK-FB. Interestingly, a negative correlation between amounts of CK-FB and CK-MET released in the supernatants was identified, revealing that bacteria selectively secrete relatively high levels of CK-FB, which are considered the most biologically active forms of CK. No glucosylCK conjugates were detected, and this is consistent with previously reported evolutionary patterns of $\mathrm{CK}$ in prokaryotic organisms compared with angiosperms (Stirk and van Staden 2010). Overall, these results suggest that bacteria process CK-NT and $\mathrm{CK}-\mathrm{RB}$ into $\mathrm{CK}-\mathrm{FB}$ and that this biologically active form is preferentially secreted outside bacterial cells. At this point, it would be interesting to compare our results with similar data available in different bacteria tested in other studies. However,

Table 3. Cytokinin (CK) concentration in bacterial cells and surrounding media of Sinorhizobium meliloti strains nodulating Medicago spp. host plants (Rm41 and AK631) or nonnodulating (ZB138)

\begin{tabular}{|c|c|c|c|}
\hline & 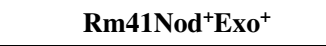 & $\mathrm{Rm}^{4} \mathrm{Nod}^{+} \mathrm{Exo}^{-} \mathrm{AK} 631$ & Rm41Nod $^{-} \mathbf{E x o}^{-}$ZB138 \\
\hline \multicolumn{4}{|l|}{ Cell pellets } \\
\hline \multicolumn{4}{|l|}{ Nucleotides (NT) } \\
\hline trans-Zeatin riboside- $5^{\prime}$-monophosphate $(t \mathrm{ZNT})$ & $1.36 \mathrm{E}-11 \pm 0.69 \mathrm{E}-11 \mathrm{NS}$ & $0.75 \mathrm{E}-11 \pm 0.08 \mathrm{E}-11$ & $0.64 \mathrm{E}-11 \pm 0.12 \mathrm{E}-11$ \\
\hline cis-Zeatin riboside-5'-monophosphate (cisZNT) & $7.16 \mathrm{e}-11 \pm 1.81 \mathrm{e}-11 \mathrm{a}$ & $4.11 \mathrm{e}-11 \pm 0.64 \mathrm{e}-11 \mathrm{~b}$ & $3.68 \mathrm{e}-11 \pm 0.00 \mathrm{e}-11 \mathrm{~b}$ \\
\hline $\mathrm{N}^{6}$-isopentyladenosine-5'-monophosphate (iPNT) & $7.20 \mathrm{E}-11 \pm 3.28 \mathrm{E}-11 \mathrm{NS}$ & $9.24 \mathrm{E}-11 \pm 0.60 \mathrm{E}-11$ & $9.21 \mathrm{E}-11 \pm 0.97 \mathrm{E}-1$ \\
\hline Total NT & $15.7 \mathrm{E}-11 \pm 5.78 \mathrm{E}-11 \mathrm{NS}$ & $14.1 \mathrm{E}-11 \pm 1.32 \mathrm{E}-11$ & $13.5 \mathrm{E}-11 \pm 1.09 \mathrm{E}-11$ \\
\hline \multicolumn{4}{|l|}{ Ribosides (RB) } \\
\hline Cis-zeatin riboside (cisZR) & $0.73 \mathrm{E}-11 \pm 0.21 \mathrm{E}-11 \mathrm{a}$ & $0.15 \mathrm{E}-11 \pm 0.02 \mathrm{E}-11 \mathrm{~b}$ & $0.33 \mathrm{E}-11 \pm 0.07 \mathrm{E}-11 \mathrm{~b}$ \\
\hline $\mathrm{N}^{6}$-isopentyladenosine (iPR) & $2.65 \mathrm{E}-11 \pm 0.46 \mathrm{E}-11 \mathrm{NS}$ & $2.06 \mathrm{E}-11 \pm 0.40 \mathrm{E}-11$ & $1.62 \mathrm{E}-11 \pm 0.27 \mathrm{E}-11$ \\
\hline Total RB & $3.38 \mathrm{E}-11 \pm 0.67 \mathrm{E}-11 \mathrm{a}$ & $2.21 \mathrm{E}-11 \pm 0.42 \mathrm{E}-11 \mathrm{ab}$ & $1.95 E-11 \pm 0.34 E-11 b$ \\
\hline \multicolumn{4}{|l|}{ Free Bases (FB) } \\
\hline $\mathrm{N}^{6}$-isopentyladenine (iP) & $29.5 \mathrm{E}-11 \pm 10.7 \mathrm{E}-11 \mathrm{NS}$ & $15.9 \mathrm{E}-11 \pm 3.24 \mathrm{E}-11$ & $19.5 \mathrm{E}-11 \pm 2.50 \mathrm{E}-11$ \\
\hline Total FB & $29.5 \mathrm{E}-11 \pm 10.7 \mathrm{E}-11 \mathrm{NS}$ & $15.9 \mathrm{E}-11 \pm 3.24 \mathrm{E}-11$ & $19.5 \mathrm{E}-11 \pm 2.50 \mathrm{E}-11$ \\
\hline \multicolumn{4}{|l|}{ Methyl-thiols (MET) } \\
\hline 2-Methylthio-trans-zeatin (2MeSZ) & $60.0 \mathrm{E}-11 \pm 8.93 \mathrm{E}-11 \mathrm{NS}$ & $70.9 \mathrm{E}-11 \pm 19.3 \mathrm{E}-11$ & $40.1 \mathrm{E}-11 \pm 6.52 \mathrm{E}-11$ \\
\hline 2-Methylthio-trans-zeatin riboside (2MeSZR) & $0.90 \mathrm{E}-11 \pm 0.25-11 \mathrm{NS}$ & $1.65 \mathrm{E}-11 \pm 0.25 \mathrm{E}-11$ & $0.87 \mathrm{E}-11 \pm 0.38 \mathrm{E}-11$ \\
\hline 2-Methylthio- $\mathrm{N}^{6}$-isopentyladenine $(2 \mathrm{MeSiP})$ & $19.7 \mathrm{E}-11 \pm 3.58 \mathrm{E}-11 \mathrm{~b}$ & $51.8 \mathrm{E}-11 \pm 7.55 \mathrm{E}-11 \mathrm{a}$ & $26.3 \mathrm{E}-11 \pm 22.6 \mathrm{E}-11 \mathrm{~b}$ \\
\hline 2-Methylthio- $\mathrm{N}^{6}$-isopentyladenosine (2MeSiPA) & $1.03 \mathrm{E}-11 \pm 0.32 \mathrm{E}-11 \mathrm{~b}$ & $1.40 \mathrm{E}-11 \pm 0.30 \mathrm{E}-11 \mathrm{a}$ & $0.44 \mathrm{E}-11 \pm 0.18 \mathrm{E}-11 \mathrm{~b}$ \\
\hline Total MET & 81.6E-11 $\pm 13.1 \mathrm{E}-11$ ab & $126 \mathrm{E}-11 \pm 27.4 \mathrm{E}-11 \mathrm{a}$ & $67.7 E-11 \pm 29.7 E-11 b$ \\
\hline \multicolumn{4}{|l|}{ Supernatants } \\
\hline \multicolumn{4}{|l|}{ NT } \\
\hline$t \mathrm{ZNT}$ & $2.33 \mathrm{E}-11 \pm 1.08 \mathrm{E}-11 \mathrm{NS}$ & $0.58 \mathrm{E}-11 \pm 0.36 \mathrm{E}-11$ & $1.89 \mathrm{E}-11 \pm 1.89 \mathrm{E}-11$ \\
\hline cisZNT & $50.5 \mathrm{E}-11 \pm 8.57 \mathrm{E}-11 \mathrm{a}$ & $22.3 \mathrm{E}-11 \pm 10.1 \mathrm{E}-11 \mathrm{~b}$ & $17.3 \mathrm{E}-11 \pm 1.83 \mathrm{E}-11 \mathrm{~b}$ \\
\hline iPNT & $110 \mathrm{E}-11 \pm 73.6 \mathrm{E}-11 \mathrm{a}$ & $1.21 \mathrm{E}-11 \pm 0.81 \mathrm{E}-11 \mathrm{~b}$ & $9.04 \mathrm{E}-11 \pm 10.4 \mathrm{E}-11 \mathrm{~b}$ \\
\hline Total NT & $163 \mathrm{E}-11 \pm 83.2 \mathrm{E}-11$ a & 24.1E-11 $\pm 11.3 E-11 b$ & 28.2E-11 $\pm 14.1 E-11 b$ \\
\hline \multicolumn{4}{|l|}{$\mathrm{RB}$} \\
\hline cisZR & $6.61 \mathrm{E}-11 \pm 2.96 \mathrm{E}-11 \mathrm{NS}$ & $2.65 \mathrm{E}-11 \pm 0.78 \mathrm{E}-11$ & $2.15 \mathrm{E}-11 \pm 0.69 \mathrm{E}-11$ \\
\hline $\mathrm{iPR}$ & $29.2 \mathrm{E}-11 \pm 9.89 \mathrm{E}-11 \mathrm{a}$ & $3.30 \mathrm{E}-11 \pm 0.62 \mathrm{E}-11 \mathrm{~b}$ & $3.33 \mathrm{E}-11 \pm 0.34 \mathrm{E}-11 \mathrm{~b}$ \\
\hline Total RB & $35.8 \mathrm{E}-11 \pm 12.8 \mathrm{E}-11 \mathrm{a}$ & $5.95 E-11 \pm 1.4 E-11 b$ & $5.48 E-11 \pm 1.03 E-11 b$ \\
\hline \multicolumn{4}{|l|}{ FB } \\
\hline trans-Zeatin & $55.1 \mathrm{E}-11 \pm 18.4 \mathrm{E}-11 \mathrm{NS}$ & $43.7 \mathrm{E}-11 \pm 5.79 \mathrm{E}-11$ & $45.8 \mathrm{E}-11 \pm 2.42 \mathrm{E}-11$ \\
\hline iP & $675 \mathrm{E}-11 \pm 112 \mathrm{E}-11 \mathrm{a}$ & $410 \mathrm{E}-11 \pm 59.3 \mathrm{E}-11 \mathrm{~b}$ & $511 \mathrm{E}-11 \pm 34.1 \mathrm{E}-11 \mathrm{ab}$ \\
\hline Total FB & $730 \mathrm{E}-11 \pm 130 \mathrm{E}-11$ a & $454 \mathrm{E}-11 \pm 65.1 \mathrm{E}-11 \mathrm{~b}$ & $557 \mathrm{E}-11 \pm 36.5 \mathrm{E}-11 \mathrm{ab}$ \\
\hline \multicolumn{4}{|l|}{ MET } \\
\hline $2 \mathrm{MeSZ}$ & $159 \mathrm{E}-10 \pm 278 \mathrm{E}-11 \mathrm{a}$ & $983 \mathrm{E}-11 \pm 57.7 \mathrm{E}-11 \mathrm{~b}$ & $978 \mathrm{E}-11 \pm 69.2 \mathrm{E}-11 \mathrm{~b}$ \\
\hline 2MeSZR & $76.5 \mathrm{E}-11 \pm 20.1 \mathrm{E}-11 \mathrm{a}$ & $22.0 \mathrm{E}-11 \pm 3.97 \mathrm{E}-11 \mathrm{~b}$ & $13.0 \mathrm{E}-11 \pm 1.26 \mathrm{E}-11 \mathrm{~b}$ \\
\hline $\mathrm{MeSiP}$ & $220 \mathrm{E}-11 \pm 64.5 \mathrm{E}-11 \mathrm{a}$ & $82.6 \mathrm{E}-11 \pm 10.7 \mathrm{E}-11 \mathrm{~b}$ & $160 \mathrm{E}-11 \pm 10.6 \mathrm{E}-11 \mathrm{ab}$ \\
\hline MeSiPA & $54.8 \mathrm{E}-11 \pm 26.9 \mathrm{E}-11 \mathrm{a}$ & $8.07 \mathrm{E}-11 \pm 5.43 \mathrm{E}-11 \mathrm{~b}$ & $4.51 \mathrm{E}-11 \pm 1.15 \mathrm{E}-11 \mathrm{~b}$ \\
\hline Total MET & $194 \mathrm{E}-10 \pm 38.9 \mathrm{E}-10 \mathrm{a}$ & $109 \mathrm{E}-10 \pm 7.78 \mathrm{E}-10 \mathrm{~b}$ & $115 \mathrm{E}-10 \pm 8.22 \mathrm{E}-10 \mathrm{~b}$ \\
\hline
\end{tabular}

${ }^{a}$ After centrifugation, bacterial cell pellets and supernatants were analyzed by liquid chromatography tandem mass spectrometry separately for CK contents. Concentrations are given in picomoles per cell \pm standard error. Results shown are the mean values of three biological replicates. A Duncan's multiple range test was performed to determine significant differences between strains for each CK type. Means are followed by letters only when significant differences were detected at the rejection level $P=0.05$. NS indicates lack of significant differences between the strains. 
past studies about bacterial CK profiling were fragmentary and did not discriminate $\mathrm{CK}$ production versus secretion and, thus, were not amenable to insightful comparisons.

In addition to Nod factor bacterial signals, CK were shown to be essential for nodule organogenesis (Frugier et al. 2008; Oldroyd 2007). In addition to plant-synthesized hormones, a contribution of bioactive CK produced by rhizobia could exist, so we compared CK produced by $S$. meliloti nodulating strains (Rm41 and the AK631 exo $^{-}$derivative) and a nonnodulating strain (ZB138) (Kondorosi et al. 1984; Putnoky et al. 1988). The ExoB mutation was initially introduced in Rm41, generating the AK631 strain, in order to allow an easier in vitro growth of bacteria, leading to a more compact structure of the colonies than for the Rm41 WT strain, which produces large amounts of EPS. This mutant strain, however, still shows a WT nodulation on Medicago sativa or Medicago truncatula host roots (Kondorosi et al. 1984; this study). All three S. meliloti strains were able to synthesize and secrete CK, with CK-MET types being, once again, the most abundant in bacteria, together with CK-FB in the supernatants. This revealed that the nod strain still produces and secretes bioactive CK despite its inability to initiate nodule organogenesis on Medicago truncatula or Medicago sativa host plant roots. A similar nod $S$. meliloti mutant engineered to synthesize large amounts of trans-zeatin was previously demonstrated to induce the formation of nodulelike structures devoid of bacteria on Medicago sativa roots (Cooper and Long 1994). These pseudo-nodules may, therefore, be formed because of the high level of $\mathrm{CK}$ production attained in this transgenic strain. Accordingly, exogenous application of $\mathrm{CK}$, without any bacteria, is sufficient to trigger initial steps of nodule organogenesis in Medicago sativa (Bauer et al. 1996) or even to induce nodule-like structures in Lotus japonicus (Heckmann et al. 2011). The differential response to exogenous CK observed depending on species or even Lotus genotypes was, however, not correlated to host-plant nodulation efficiency.

Overall, this study demonstrates that all symbiotic rhizobia tested were able to produce and secrete a similar CK mix, including biologically active hormones. This ability is comparable to that observed for other rhizospheric bacteria including pathogens. A nod mutant unable to nodulate Medicago truncatula or Medicago sativa host plants retains its ability to produce similar amounts of CK, suggesting that bacterial CK production is not, in itself, sufficient to induce nodulation. The question remains whether bacterial $\mathrm{CK}$ could contribute to the symbiotic interaction in a WT context or during interactions with specific symbiotic bacteria that do not produce Nod factors, such as some Bradyrhizobia spp. (Podlešáková et al. 2013). In addition, as all analyses were performed in bacterial liquid culture, it is possible that, under rhizospheric soil conditions, some plant exudates such as flavonoids may affect either CK synthesis, secretion by rhizobia, or both, as shown for auxin synthesis, which depends on activation of Nod factor synthesis (Theunis et al. 2004). Finally, as described for auxin or CK production by rhizospheric pathogenic and PGPR bacteria, potential functions for rhizobia-produced $\mathrm{CK}$ on root system development other than those that pertain to symbiotic nodulation may exist, and these have not yet been explored.

\section{MATERIALS AND METHODS}

\section{Bacterial strains and growth conditions.}

Rhizobium strains from four species (S. meliloti, S. fredii, $S$. medicae, $M$. loti) were used in this study, as described in Table 1. Bacterial strains were maintained as $15 \%$ (vol/vol) glycerol stocks at $-80^{\circ} \mathrm{C}$. The strains were recovered by streaking directly onto GTS agar plates (Kiss et al. 1979) and were incu- bated for $48 \mathrm{~h}$. Liquid cultures were started by suspending the bacterial single colonies with a wire loop in 50-ml polypropylene culture tubes containing $12.5 \mathrm{ml}$ of liquid GTS medium. Prior to CK extraction, bacteria were cultured for $72 \mathrm{~h}$ on a rotary shaker $(250 \mathrm{rpm})$. All the cultures were grown at $30^{\circ} \mathrm{C}$. To determine cell concentration in the liquid culture, the number of colony-forming units per milliliter on agar plates was determined, using a standard serial dilution technique. Three technical replicates were analyzed for all samples, each independently repeated three times.

\section{Extraction and purification of bacterial CK.}

The profiles of $25 \mathrm{CK}$ metabolites were analyzed, including free bases, their riboside and nucleotide derivatives, as well as glucoside and methyl-thiol conjugates. Rhizobial CK were isolated and purified with a method modified from Quesnelle and Emery (2007), designed to prevent enzyme activities that could cause CK nucleotide degradation and CK isomerization.
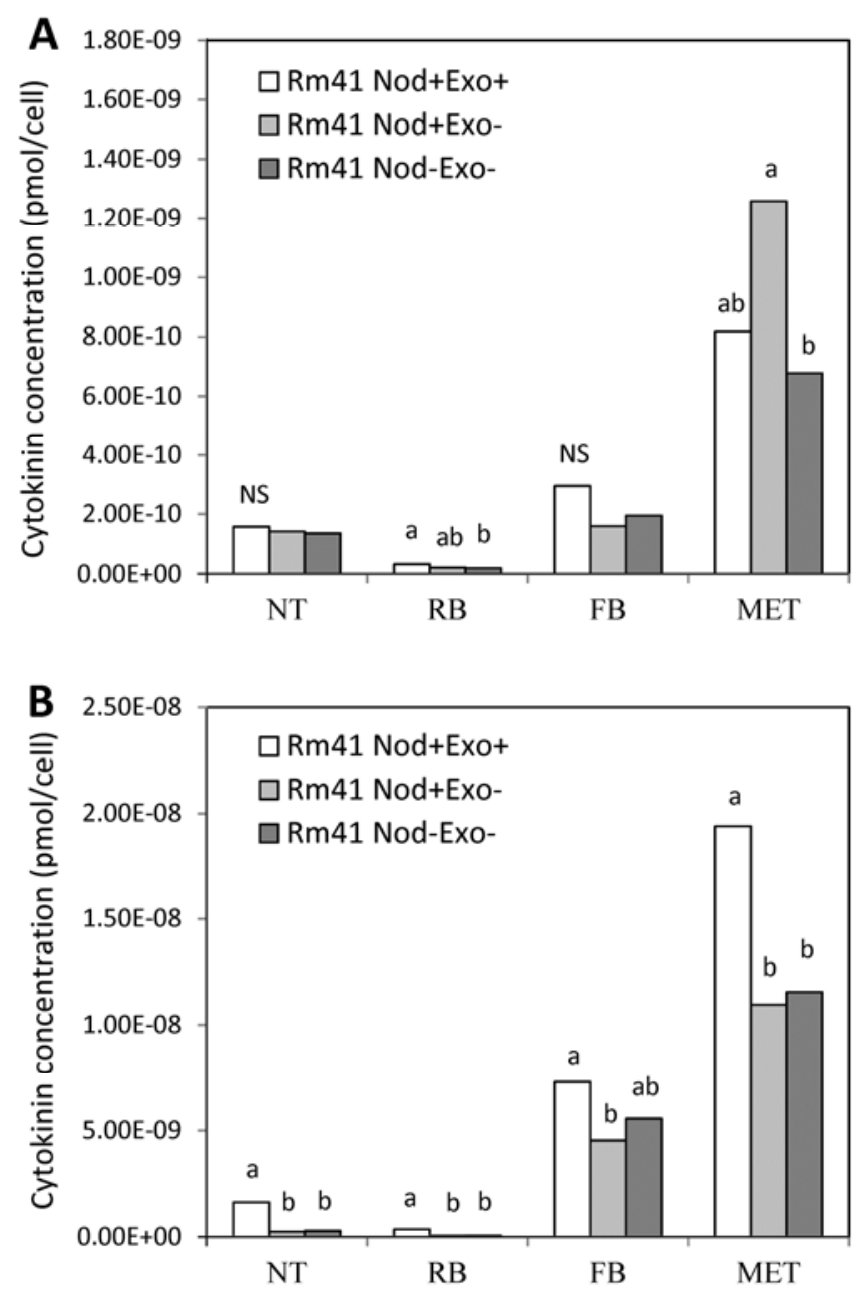

Fig. 2. Cytokinin (CK) concentration in bacterial cells and surrounding media of Sinorhizobium meliloti strains nodulating Medicago host plants (Rm41 and AK631) or nonnodulating (nod ${ }^{-}$; ZB138). Three related $S$. meliloti strains were analyzed in parallel: two nodulating strains, $\mathrm{Rm} 41$ $\left(\right.$ nod $^{+}$, exo $\left.^{+}\right)$and AK631 $\left(\right.$nod $^{+}$, exo $\left.^{-}\right)$, as well as one nonnodulating strain,

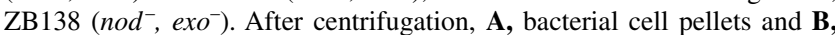
supernatants were analyzed by liquid chromatography-tandem mass spectrometry separately for CK contents. The concentration of CK types (FB, $\mathrm{RB}, \mathrm{NT}, \mathrm{MET}$ ) is expressed in picomoles per cell. Results shown are the mean values of three biological replicates. A Duncan's multiple range test was performed to determine significant differences between strains for each CK type. Means are followed by letters only when significant differences were detected at the rejection level $P=0.05$. NS indicates lack of significant differences between the strains. 
Independent extractions were performed for bacterial pellets and cell-free supernatants after $16 \mathrm{~min}$ of centrifugation at $4,000 \times g$. Medium not inoculated with rhizobium was also prepared and subjected to analysis to determine whether any interfering media components co-eluted with CK standards.

Fresh weight of cell pellets and volume of supernatants were recorded. Cell pellet and clarified supernatant samples were vortexed in $1 \mathrm{ml}$ of cold $\left(-20^{\circ} \mathrm{C}\right)$ modified Bieleski extraction solvent $\left(\mathrm{CH}_{3} \mathrm{OH}: \mathrm{H}_{2} \mathrm{O}: \mathrm{HCOOH}\right.$ [15:4:1, vol/vol/vol] $)$ with zirconium oxide grinding beads (Comeau Technique Ltd., Vaudreuil-Dorion, Canada). Ten nanograms of each of the deuterated internal standard CK (Table 2) (OlChemim Ltd., Olomouc, Czech Republic) were added to the samples. Since deuterated standards of cis Z and cisZR are not commercially available, the levels of these two compounds were quantified based on the recovery of the deuterated standards of the corresponding trans-compounds. Samples were allowed to extract passively overnight at $-20^{\circ} \mathrm{C}$. Cell pellets were removed by centrifugation $(10 \mathrm{~min}$ at $2,800 \times g)$, the obtained extracts were collected, and samples were re-extracted with $1 \mathrm{ml}$ of Bieleski buffer at $-20^{\circ} \mathrm{C}$. The remaining solids were separated by centrifugation and discarded, and the pooled extracts were evaporated to dryness at $35^{\circ} \mathrm{C}$ under vacuum (Model SPD111V; Thermo Scientific, Ottawa, Canada).

To purify and concentrate metabolites for LC-MS/MS, the extraction residues were reconstituted in $200 \mu \mathrm{l}$ of $1 \mathrm{M}$ $\mathrm{HCOOH}$ ( $\mathrm{pH}$ 1.4). The hormone-containing fraction was purified and concentrated on a mixed mode, reverse-phase, cationexchange SPE cartridge (Oasis MCX 6cc; Waters, Mississauga, Canada) as described by Kojima and associates (2009), with modifications (Farrow and Emery 2012). Cartridges were activated with high-performance liquid chromatography (HPLC) grade $\mathrm{CH}_{3} \mathrm{OH}$ and were equilibrated using $1 \mathrm{M}$ $\mathrm{HCOOH}$ ( $\mathrm{pH}$ 1.4). After equilibration, each sample was loaded and washed with $1 \mathrm{M} \mathrm{HCOOH}(\mathrm{pH}$ 1.4). CK fractions were eluted based on their chemical properties. CK-NT were eluted first with $0.35 \mathrm{M} \mathrm{NH}_{4} \mathrm{OH}$. CK-FB, CK-RB, CK-MET, and glucosides were retained based on charge and hydrophobic properties and, thus, were eluted last, using $0.35 \mathrm{M} \mathrm{NH}_{4} \mathrm{OH}$ in $60 \%$ [vol/vol] $\mathrm{CH}_{3} \mathrm{OH}$. Each fraction was evaporated to dryness at $35^{\circ} \mathrm{C}$ under vacuum.

Because CK-NT cannot be analyzed directly with our methods, they were dephosphorylated by overnight incubation with about 3 units of alkaline phosphatase (CIP; New England BioLabs Ltd., Pickering, Canada) in $1 \mathrm{ml}$ of $0.1 \mathrm{M}$ ethanolamine$\mathrm{HCl}\left(\mathrm{pH} \mathrm{10.4)}\right.$ at $37^{\circ} \mathrm{C}$. The resulting CK-RB were dried at $35^{\circ} \mathrm{C}$ under vacuum. The samples were reconstituted in double-distilled water $\left(\mathrm{dd}-\mathrm{H}_{2} \mathrm{O}\right)$ and were further isolated on a reversed-phase $\mathrm{C}_{18}$ solid phase extraction column (Canadian Life Science, Peterborough, Canada), which was first activated with $\mathrm{CH}_{3} \mathrm{OH}$ and equilibrated using dd $-\mathrm{H}_{2} \mathrm{O}$. Samples containing nucleosides were loaded onto the $\mathrm{C}_{18}$ cartridge and were allowed to pass through the column by gravity. The sorbent was washed with dd- $\mathrm{H}_{2} \mathrm{O}$. CK-RB were eluted using $100 \%$ $\mathrm{CH}_{3} \mathrm{OH}$ and eluents were evaporated at $35^{\circ} \mathrm{C}$ under vacuum.

Prior to LC-MS/MS analysis, all samples were rinsed with starting conditions buffer $\left(\mathrm{CH}_{3} \mathrm{CN}: \mathrm{CH}_{3} \mathrm{COOH}: \mathrm{ddH}_{2} \mathrm{O}\right.$ [5:0.08:94.92, vol/ $\mathrm{vol} / \mathrm{vol}])$ and were centrifuged at 2,300 $\times g$ for $10 \mathrm{~min}$ to remove debris (Thermo Scientific). The supernatants were stored at $-20^{\circ} \mathrm{C}$ until further processing.

\section{LC-(ESI+)-MS/MS conditions for bacterial CK analysis.}

Purified CK were identified and quantified by LC-(ESI+)MS/MS (Agilent 1100 series HPLC connected to a Sciex Applied Biosystem 5500 API mass spectrometer), according to the conditions outlined in Farrow and Emery (2012). An aliquot was injected on a Luna $\mathrm{C}_{18}$ reversed-phase column $(3 \mu \mathrm{m}$,
$150 \times 2.0 \mathrm{~mm}$; Phenomenex, Torrance, Canada), and the CK were eluted with an increasing gradient of $0.08 \% \mathrm{CH}_{3} \mathrm{COOH}$ in $\mathrm{CH}_{3} \mathrm{CN}$ (A) mixed with $0.08 \% \mathrm{CH}_{3} \mathrm{COOH}$ in $\mathrm{ddH}_{2} \mathrm{O}$ (B), at a flow rate of $0.2 \mathrm{ml} \mathrm{min}^{-1}$. The initial conditions were $5 \% \mathrm{~A}$ and $95 \% \mathrm{~B}$, changing linearly in $17 \mathrm{~min}$ to $95 \% \mathrm{~A}$ and $5 \% \mathrm{~B}$. Conditions remained constant for $5 \mathrm{~min}$, and then, immediately returned back to initial conditions for $18 \mathrm{~min}$. The effluent was introduced into the electrospray source using conditions specific for each CK, and quantification was obtained by multiple reaction monitoring of the protonated intact $\mathrm{CK}$ molecule $[\mathrm{M}+\mathrm{H}]^{+}$and the specific product ion (Farrow and Emery 2012).

\section{Statistical analysis.}

The data were processed with the Analyst (v. 1.5) quantification software (AB Sciex, Framingham, MA, U.S.A.) to determine peak area according to isotope dilution analysis. Concentration of $\mathrm{CK}$ types (FB, RB, NT, MET) in the different WT strains is expressed as a percentage share of the total CK pool that was produced and secreted (Fig. 1A and B) or as picomoles per cell for the bacterial cells pellet and picomoles per contributing cell for the cell-free supernatant for the comparison between Rm41 WT and mutant strains (Table 3). A Duncan's multiple range test was performed to determine significant differences for each CK type between the tested strains $(P=0.05, n=3)$.

\section{ACKNOWLEDGMENTS}

We would like to thank K. Szczyglowski from Agriculture \& Agri Food Canada, London for providing the $M$. loti strain, P. Mergaert from ISV, Gif-sur-Yvette, France for providing S. meliloti, fredii and medicae strains, and M. Brault (ISV, Gif-sur-Yvette, France) for helpful discussions. Work in the F. Frugier laboratory was supported by the LEGUROOT French ANR project. Work in the R. J. Neil Emery laboratory was supported by a Natural Science and Engineering Research Council of Canada Discovery Grant. A. Kisiala and C. Laffont participated in the design, analysis and interpretation of the data, as well as in drafting the article. R. J. N. Emery and F. Frugier participated in the conception, design, and interpretation of the data, as well as revised the article. All authors have approved the final version of the article.

\section{LITERATURE CITED}

Bauer P., Ratet, P., Crespi, M. D., Schultze, M., and Kondorosi, A. 1996. Nod factors and cytokinins induce similar cortical cell division, amyloplast deposition and MsEnod12A expression patterns in alfalfa roots. Plant J. 10:91-105.

Boiero, L., Perrig, G., Masciarelli, O., Penna, C., Cassan, F., and Luna. V. 2007. Phytohormone production by three strains of Bradyrhizobium japonicum and possible physiological and technological implications. Appl. Microbiol. Biot. 74:874-880.

Cooper, J. B., and Long, S. R. 1994. Morphogenetic rescue of Rhizobium meliloti nodulation mutants by trans-Zeatin secretion. Plant Cell 6:215225.

Depuydt, S., Trenkamp, S., Fernie, A. R., Elftieh, S., Renou, J. P., Vuylsteke, M., Holsters, M., and Vereecke, D. 2009. An integrated genomics approach to define niche establishment by Rhodococcus fascians. Plant Physiol. 149:1366-1386.

Eason, J. R., Morris, R. O., and Jameson, P. E. 1996. The relationship between virulence and cytokinins production by Rhodococcus fascians (Tilford 1936) Goodfellow 1984. Plant Physiol. 45:323-331.

Farrow, S. C., and Emery, R. J. N. 2012. Concurrent profiling of indole-3acetic acid, abscisic acid, and cytokinins and structurally related purines by high-performance-liquid-chromatography tandem electrospray mass spectrometry. Plant Met. 8-42.

Frugier, F., Kosuta, S., Murray, J. D., Crespi, M., and Szczyglowski, K. 2008. Cytokinin: Secret agent of symbiosis. Trends Plant Sci. 13:115-20.

Fukuhara, H., Minakawa, Y., Akao, S., and Minamisawa, K. 1994. The involvement of indole-3-acetic acid produced by Bradyrhizobium elkanii in nodule formation. Plant Cell Physiol. 35:1261-1265.

Giraud, E., Moulin, L., Vallenet, D., Barbe, V., Cytryn, E., Avarre, J. C., Jaubert, M., Simon, D., Cartieaux, F., Prin, Y., Bena, G., Hannibal, L., 
Fardoux, J., Kojadinovic, M., Vuillet, L., Lajus, A., Cruveiller, S., Rouy, Z., Mangenot, S., Segurens, B., Dossat, C., Franck, W. L., Chang, W. S., Saunders, E., Bruce, D., Richardson, P., Normand, P., Dreyfus, B., Pignol, D., Stacey, G., Emerich, D., Verméglio, A., Médigue, C., and Sadowsky, M. 2007. Legumes symbioses: Absence of Nod genes in photosynthetic bradyrhizobia. Science 316:1307-1312.

Gonzalez-Rizzo, S., Crespi, M., and Frugier, F. 2006. The Medicago truncatula CRE1 cytokinin receptor regulates lateral root development and early symbiotic interaction with Sinorhizobium meliloti. Plant Cell 18:2680-2693.

Kaneshiro, T., and Kwolek, W. F. 1985. Stimulated nodulation of soybeans by Rhizobium japonicum mutant (B-14075) that catabolizes the conversion of tryptophan to indol-3yl-acetic acid. Plant Science 42:141-146.

Heckmann, A. B., Sandal, N., Bek, A. S., Madsen, L .H., Jurkiewicz, A., Nielsen, M. W., Tirichine, L., and Stougaard, J. 2011. Cytokinin induction of root nodule primordia in Lotus japonicus is regulated by a mechanism operating in the root cortex. Mol. Plant Microbe Interact. 24:1385-1395.

Kiss, G. B., Yincze, E., Kalman, Z., Forrai, T., and Kondorosi, A. 1979. Genetic and biochemical analysis of mutants affected in nitrate reduction in Rhizobiurn rneliloti. J. Gen. Microbiol. 113:105-118.

Kojima, M., Kamada-Nobusada, T., Komatsu, H., Takei, K., Kuroha, T., Mizutani, M., Ashikari, M., Ueguchi-Tanaka, M., Matsuoka, M., Suzuki, K., Sakakibara, H. 2009. Highly sensitive and high-throughput analysis of plant hormones using MS-probe modification and liquid chromatography-tandem mass spectrometry: An application for hormone profiling in Oryza sativa. Plant Cell Physiol. 50:1201-1214.

Kondorosi, E., Banfalvi, Z., and Kondorosi, A. 1984. Physical and genetic analysis of a symbiotic region of Rhizobium meliloti: Identification of nodulation genes. Mol. Gen. Genet. 193:445-452.

Leigh, J. A., Signer, E. R., and Walker, G. C. 1985. Exopolysaccharide-deficient mutants of Rhizobium meliloti that form ineffective nodules. Proc. Natl. Acad. Sci. USA 82:6231-6235.

Lichter, A., Manulis, S., Sagee, O., Gafni, Y., Gray, J., Meilan, R., Morris, R. O., and Barash, I. 1995. Production of cytokinins by Ervinia herbicola pv. Gypsophilae and isolation of a locus conferring cytokinins biosynthesis. Mol. Plant Microbe Interact. 8:114-121.

Meade, H. M., and Singer, E. R. 1977. Genetic mapping of Rhizobium meliloti. Proc. Natl. Acad. Sci. USA 74:2076-2078.

Murray, J. D., Karas, B. J., Sato, S., Tabata, S., Amyot, L., and Szczyglowski K. 2007. A cytokinin perception mutant colonized by Rhizobium in the absence of nodule organogenesis. Science 315:101-104.

Noreen, S., Schlaman, H. R. M., Bellogin, R. A., Buendia-Claveria, A. M., Espuny, M. R., Harteveld, M., Medina, C., Ollero, F. J., Olsthoorn, M. M. A., Soria-Diaz, M. E., Spaink, H. P., Temprano, F., Thomas-Oates, J., Vinardell, J. M., Yang, S. S., Zhang, H. Y., and Ruiz-Sainz, J. E. 2003. Alfalfa nodulation by Sinorhizobium fredii does not require sulfated Nod-factors. Funct. Plant Biol. 30:1219-1232.

Oldroyd, G. E. D. 2007. Nodules and hormones. Science 315:52-53.

Pertry, I., Vaclavíkova, K., Depuydt, S., Galuszka, P., Spíchal, L., Temmerman, W., Stes, E., Schmulling, T., Kakimoto, T., Van Montagu, M. C. E., Strnad, M., Holsters, M., Tarkowski, P., and Vereecke, D. 2009. Identification of Rhodococcus fascians cytokinins and their modus operandi to reshape the plant. P.N.A.S. 106:929-934.

Phillips, D. A., and Torrey, J. G. 1972. Studies on cytokinin production by Rhizobium. Plant Physiol. 49:11-15.
Plet, J., Wasson, A., Ariel, F., Le Signor, C., Baker, D., Mathesius, U., Crespi, M., and Frugier, F. 2011. MtCRE1-dependent cytokinin signaling integrates bacterial and plant cues to coordinate symbiotic nodule organogenesis in Medicago truncatula. Plant J. 65:622-633.

Pocard, J. A., Vincent, N., Boncompagni, E., Smith, L. T., Poggi, M. C., and Le Rudulier, D. 1997. Molecular characterization of the bet genes encoding glycine betaine synthesis in Sinorhizobium meliloti 102F34. Microbiology 143:1369-1379.

Putnoky, P., Grosskopf, E., Cam Ha, D. T., Kiss, G. B., and Kondorosi, A. 1988. Rhizobium fix genes mediate at least two communication steps in symbiotic nodule development. J. Cell. Biol. 106:597-607.

Quesnelle, P. E., and Emery, R. J. N. 2007. cis-Cytokinins that predominate in Pisum sativum during early embryogenesis will accelerate embryo growth in vitro. Can. J. Bot. 85:91-103.

Podlešáková, K., Fardoux, J., Patrel, D., Bonaldi, K., Novák, O.,Strnad, M.,Giraud, E., Spíchal, L., and Nouwen, N. 2013. Rhizobial synthesized cytokinins contribute to but are not essential for the symbiotic interaction between photosynthetic bradyrhizobia and Aeschynomene legumes. Mol. Plant Microbe Interact. 26:1232-1238.

Roche, P., Lerouge, P., Ponthus, C., and Promé, J. C. 1991. Structural determination of bacterial nodulation factors involved in the Rhizobium meliloti-alfalfa symbiosis. J. Biol. Chem. 266:10933-10940.

Romanov, G. A. 2011. The discovery of cytokinin receptors and biosynthesis of cytokinins: A true story. Rus. J. Plant Physiol. 58:743-747.

Rome, S., Fernandez, M. P., Brunel, B., Normand, P., and Cleyet-Marel, J. C. 1996. Sinorhizobium medicae sp. nov., isolated from annual Medicago spp. Int. J. Syst. Bacteriol. 46:972-980.

Saharan, B. S., and Nehra, V. 2011. Plant growth promoting rhizobacteria: A Critical Review. Life Sci. Med. Res. 21:1-30.

Sakakibara, H. 2006. Cytokinins: Activity, biosynthesis, and translocation. Annu. Rev. Plant Biol. 57:431-449.

Stes, E., Vandeputte, O. M., El Jaziri, M., Holsters, M., and Vereecke, D. 2011. A successful bacterial coup d'état: How Rhodococcus fascians redirects plant development. Annu. Rev. Phytopathol. 49:69-86.

Stevens, G. A., and Berry, A. M. 1988. Cytokinin secretion by Frankia sp., HFPArI3 in defined medium. Plant Physiol. 87:15-16.

Stirk, W., and van Staden, J. 2010. Flow of cytokinins through the environment. Plant Growth Regul. 62:101-116.

Sturtevant, D. B., and Taller, B. J. 1989. Cytokinin production by Bradyrhizobium japonicum. Plant Physiol. 89:1247-1252.

Szczyglowski, K., Shaw, R. S., Wopereis, J., Copeland, S., Hamburger, D., Kasiborski, B., Dazzo, F. B., and Bruijn, F. J. 1998. Nodule organogenesis and symbiotic mutants of the model legume Lotus japonicus. Mol. Plant Microbe Interact. 11:684-697.

Theunis, M., Kobayashi, H., Broughton, W. J., and Prinsen, E. 2004. Flavonoids, NodD1, NodD2, and Nod-box NB15 modulate expression of the $y 4 \mathrm{wEFG}$ locus that is required for indole-3-acetic acid synthesis in Rhizobium sp. strain NGR234. Mol. Plant Microbe Interact. 17:11531161.

Timmusk, S., Nicander, B., Granhall, U., and Tillberg, E. 1999. Cytokinin production by Paenibacillus polymyxa. Soil Biol. Biochem. 31:18471852.

Tirichine, L., Sandal, N., Madsen, L. H., Radutoiu, S., Albrektsen, A. S., Sato, S., Asamizu, E., Tabata, S., and Stougaard, J. 2007. A gain-offunction mutation in a cytokinin receptor triggers spontaneous root nodule organogenesis. Science 315:104-107. 